\title{
Exploration and Practice of Advertising Design Professional Education in Higher Vocational Colleges
}

\author{
Yangle \\ School of Art Engineering of Tianjin Vocational Institute \\ Tianjin China \\ 68444147@qq.com
}

\begin{abstract}
In this paper, the advertisement design major of Higher Vocational Teaching Reform in several aspects are analyzed, such as the occupation of higher vocational teacher training; the depth of school-enterprise cooperation, training skilled personnel; to change the traditional teaching environment, the classroom turned professional studio, creating practice and employment environment good, aims to explore the development and practice of deepening the reform of teaching in Higher Vocational education.
\end{abstract}

Keywords-Vocational Major of Advertising Design High skill talents Education practice

\section{INTRODUCTION}

The higher occupation education is to cultivate students' goal is to obtain the actual capacity required for a particular occupation or occupation groups in education, and provides the path to a certain occupation development. In the process of education and teaching to emphasize the development of skills and knowledge and ability of special subject as the goal, and delivery of a large number of high-end skilled talents for the construction of a modern industrial system of national education.

Advertising design specialty of higher vocational education is based on social development and market economy to be engaged in advertising design industry talents emerge as the times require professional. Along with China's economic rise, the rapid influx of domestic and foreign products, the advertising market competition intensifies. As the entire consumer population of ad information communication has a great demand and dependence. The current social advertising everywhere, the mass media provides the information people get all kinds of effective advertising information. Advertising industry boom, the number of advertising professionals demand is climbing. Although the annual university graduates into the advertising industry, but the modern advertisement design talents of all colleges and universities in the reality facing the market demand is still a lack of. Requirements for graduates employment advertising industry can quickly enter the state, and can have a more comprehensive knowledge reserve, teamwork and good practical. But there is a big difference between knowledge and society, college graduates in the school needs, talents are not quickly, efficiently serve the society. Although the higher vocational graduates occupation teaching training, but the actual situation is still unable to meet the education and society and industry standards. When we in the analysis of the follow-up survey of student employment after the discovery, many excellent graduates out of school, although with professional skills and occupation excellent warm in school, but to accept the training of graduate student, the enterprise does not warm. To some well-known large enterprises in the advertising industry candidates, often run into a wall, these enterprises believe that the students lack of skilled work experience. So many students employment after two or three years or even longer period of time, only small and medium-sized enterprises engaged in general, only students through continuous efforts, with their own ability and the accumulation of experience, to gradually move to a wellknown Enterprise Inc, eventually realize their occupation ideal.

This research we now or in the higher vocational education theory, systematic and integrity of school education as the main character, students sometimes lack the needed by the society of knowledge and skills. The actual level of the students graduate employment has not reached the general industry standards, large well-known enterprises in the selection of personnel, to adapt to higher vocational graduates job skills in doubt, students can complete the social practice need to develop skills in working process a large number of small and medium-sized enterprises. If this phenomenon exists for a long time, we need to fully to the enterprise industry job demand understanding, lack of higher vocational education to find out the maturity model has been made in the teaching of higher vocational education, teaching in practice to meet the high quality applied talents of technology industries in the area of production, practice, management and service of the need for training objectives, targeted to carry out " occupation " of the training. According to this advertising design professional education, should focus on training the students skills, according to a certain range of occupation, students can become good at the skills of a professional field of.

\section{OCCUPATION OF A VOCATIONAL SCHOOL, TEACHER TRAINING}

More teacher training efforts, enhance the professional teachers in higher vocational practical ability, the professional theory knowledge closely related to the production practice, step by step to follow the new trend of new technology, is the main way to lead students to the occupation of the road. 
Professor Keith Home, a famous British engineering education experts Salford University said very vivid, he said: " only by a surgeon qualified teachers, can in the surgical operation room develop truly surgeon " [1]. Technology application talents cultivation enterprise line of high-quality, high skills, first selection of the first practical experience, competence and qualifications of teachers is the key link, teachers' practical ability and skill level decided on the one hand, the important effect of Higher Vocational education. The current higher vocational colleges exist in the long-term mechanism of teacher training, vocational teachers engaged in teaching not only needs the rich theoretical knowledge, but also skilled practice operation skills. But the reality is there are many professional teachers are mostly from school to school, classroom teaching way naturally also followed its undergraduate postgraduate education characteristics. Of course, teachers also have the experience of front-line teachers, but due to the long engaged in the teaching work, professional experience in practice gradually from the new technology and new skills of the professional update. The teachers on the new technology and new skills training, to enhance skills essential for occupation. In fact, many teachers in the teaching process also hope to be able to enter the enterprise further study, new technologies, new concept of enterprise into the classroom. In this way is beneficial not only to the teacher and the school, more directly benefit from the students into the enterprise practice level. In formulating a series of teachers about the enterprise practice system, need to give the teacher practice time and frequency fully, in order to guarantee the quality and effect of practice.

1) Output teachers ": to ensure the teaching condition, the professional core curriculum teachers take regular output to the industry, advanced professional practice skills, for the long-term development of reserve talent of professional. The teachers involved in the advertising industry, teachers have to tease out the practice teaching theory is applied, to improve practical teaching and students' professional vocational theory divorced from the situation of traditional. On the other hand, teachers in the internship time will be the latest information advertising company in the industry, into the classroom teaching, enhance the professional knowledge and skills of the renewal and development. At the same time, teachers can also provide ideas and methods to solve the problem for the enterprises to use system experience knowledge working and teaching in the.

2) Input teachers " : the introduction of enterprise backbone, activities, industry association invited experts, Industry Association of entrepreneur lectures, teacher training.

At present most engaged in advertising design education teacher introduced resources are directly derived from the fine arts college fresh graduates, in the teaching process of occupation skill, such people often lack the experience of occupation. In the selection of the German occupation of teacher is very strict, in the higher occupation education teacher qualifications is a graduate, work in the enterprise in 5 years, just have the qualifications. So far, China's colleges and universities talent selection has not as of yet, therefore need to actively introduce advertising industry elite, expert to participate in class teaching practice, invited Industry Association experts, entrepreneurs, lectures and teacher interaction or centralized training for teachers, to broaden the practice experience and professional horizons enrich the teachers'.

For the input of teacher resource the school can also open for recruitment of part-time teachers, part-time teachers can not only deal with the social employment advertising categories of professional subdivision, update information and the professional knowledge and skills of effective measures, and the school through the recruitment of parttime teachers, can also reduce the cost of funds.

In short, the training of teachers professional practice ability through various channels, in various forms, and reach the teaching reform, the purpose of improving the teaching quality.

\section{TO CULTIVATE TALENTS, THE DEPTH OF SCHOOL- ENTERPRISE COOPERATION TWO}

School-enterprise cooperation is an important measure of vocational training, but in actual operation, the majority of enterprises to participate in the enthusiasm of schoolenterprise cooperation and curriculum development is not high. School-enterprise cooperation in the form of many only stay in the listing, visit and investigation of the enterprise practice base of the stage, the development of professional training process, the effect is not obvious. School-enterprise cooperation in recent years, the results show that, the majority of school-enterprise cooperation experience is not long, because of the lack of industry and enterprise participation, occupation education development has encountered many difficulties, enterprises can not deeply involved in the teaching reform, occupation colleges are not close to the industry enterprises and employers' demands.

In the process of the depth of cooperation development and enterprise should be found in the common interests of both sides, especially to find the interests of business point, making training mode for enterprise need talent, according to the interests of enterprises and the cooperation mode to design the teaching content. Summarize a number of schoolenterprise cooperation in recent years has been the emergence of hosting the occupation education, teaching reform occupation colleges and universities and the experience of successful enterprises, vigorously support, publicity and promotion. For example, our school and " evening news " for school-enterprise cooperation, establish agency enterprises in the school, the school of advanced equipment resources, the students establish factory in business school, increase the students further skills practice opportunities. The business enterprise can make use of their practice to reduce labor costs, if the students recruited as formal employee, then reduce training cost and adapt to the working time.

Three, to change the traditional teaching environment, the classroom turned professional studio internship and employment, create good environment

Advertising design professional students most courses are opened in ordinary traditional classrooms, multimedia classrooms, computer room. But these traditional teaching 
environment, and teaching in universities environment without distinction. Occupation education training objectives clearly pointed to the skills and knowledge to ability oriented enterprise required skills training. So whether it is from the teaching arrangements, or to the traditional teaching environment improvement, are positive steps for students' future accessibility into the enterprise working environment.

In foreign art advertising design professional many, the students in the classroom has been transformed into the actual working environment working classroom. An important part of the design and advertising practice of computer, digital image computer room, Art Lab these experimental system, has become a part of their daily classroom. All the students are implemented in a real environment, so realistic students professional role will be more intense, students would be willing to spend more time at work in the classroom. Such work, form the characteristic, in the course can not only complete the teaching practice and training task, also can use the mode of operation of the advertising company projects docking in courses. Through the development of business and related enterprises, relevant design closely combined with teaching, not only become the field of training students to learn professional, to the community, provide jobs for students work-study program, and built the advertising design professional in foreign cooperation, teaching research and technology platform.

To change the traditional teaching environment, cultivate students to integrate theory with practice, innovation spirit and practice ability, in the promotion of quality education, practical ability and innovative spirit, the mode of education, plays an irreplaceable role.

Four, in the skills competition in marketing talent and the formation of scale and characteristics, enhance employment strength

Higher vocational art students in advertising professional enrollment in the link, generally with the cultural foundation is weak, relatively loose, active, open-minded etc.. In their training should be free from serious, nervous atmosphere in the classroom, conversion to reform the examination and evaluation method in the teaching method, strengthen the occupation education measures. For example, you can organize students to participate in professional every semester in advertising design skills competition. Exchange of experience skills competition can not only strengthen the high-quality, high skills among higher vocational colleges design talent, but also to actively promote the training goal of advertising design industry in urgent need of talents. In the skills competition for the organization and implementation process also can enhance students' scientific thinking and artistic accomplishment, show the students design and production of creative ability.

Practical simulation and group than draft: in the special training for competition, teachers can adopt the practical teaching students according to the actual project of simulation. Different from the conventional teaching is, by simulating the actual way to exercise the students grasp of the overall advertising design activities and the ability of practical application, this includes advertising market survey students analysis ability, goal setting and product positioning capability, performance strategy, media selection and combination ability, advertising budgets, advertising planning ability case writing and expression ability, professional skills. In addition to simulated combat, in addition to contest the group as a unit than draft mode, exercise and training students in the skills competition in the team cooperation consciousness, the consciousness of responsibility, communication and coordination ability and active learning and exploring the comprehensive ability, let the students participate in the actual combat practice ability and professional interests are enhanced.

To carry on with the scale and characteristic of the skills competition, higher vocational colleges can actively joint enterprises or institutions of education, a number of carrying out occupation skills contest. In the competition, lets the enterprise realize the practical ability of students, it is bound to cause the advertising industry have the initiative and organized institutions, held in the skills competition. In alleviating the employment pressure, it has become an effective channel to expand students' employment.

\section{CONCLUSION}

The construction process of exploration and implementation of our vocational advertising design professional teaching in, still need to adhere to the long-term professional as the breakthrough point, according to the application of skills, practical principles, teaching mode of broad based, in order to cultivate talents for the advertising design task, in order to adapt to the business needs as the goal, continue to test teaching effects, the employment market feedback for teaching reform way, speed up the training and development of talents in Higher Vocational advertising design industry.

\section{REFERENCES}

[1] Chen Bing He. Students Skills Contest for Vocational Training, Occupation Education Value of Education in Jiangsu: 2009 ( 6 ): 6060

[2] Zhang Yong Mei. Advertisement Design College Education to Promote the Development of Chinese Advertising Industry Circle Occupation of 2007 ( 7 ): 192-193

[3] O Yue Nan. Trend of teaching reform of Higher Vocational Education of Science and Technology Plaza, 2008 ( 4 ): 242-243

[4] Jing XueLian. Higher Vocational College English Teaching Reform Trend of Journal of Yuncheng University, 2005 ( 3 ): 72-74

[5] Gong Lingling Advertisement Design in Higher Vocational Colleges Teaching Mode of Journal of Shandong Agricultural Administrators College, 2009 ( 6 ): 182-183 